\title{
Histórias de vida e compreensão empática: uma pesquisa qualitativa sobre a estimulação da competência narrativa em estudantes de saúde*
}

\author{
Life stories and empathic understanding: a qualitative research \\ on the stimulation of the narrative competence in health students
}

\author{
Cláudia de Oliveira $^{1}$ • Paulo Jesus ${ }^{2}$. Virgínia Junqueira ${ }^{3}$. \\ Lúcia da Rocha Uchôa-Figueiredo ${ }^{3}$
}

\begin{abstract}
Resumo: Este artigo objetiva compreender os efeitos da atividade de escuta, na formação de profissionais em saúde. Consiste em estudo qualitativo, com análise de entrevistas semiestruturadas, aplicadas a dezoito estudantes da Universidade Federal de São Paulo, campus Baixada Santista, de Educação Física, Fisioterapia, Nutrição, Psicologia, Serviço Social e Terapia Ocupacional. Resultados apontam que a escuta sensível afetou os estudantes qualitativamente em relação à subjetividade e à prática profissional futura. Houve, também, valorização da oferta de atendimento humanizado, além da quebra de preconceitos e paradigmas; criação de vínculo terapêutico; superação de diferenças e compreensão de si, a partir da história de vida do outro.
\end{abstract}

Palavras-chave: Ensino em saúde. Narrativa. Escuta. Alteridade. Humanização.

\begin{abstract}
This article aims to understand the effects of listening in the training of health professionals. It is a qualitative study, analyzing semi-structured interviews applied to eighteen students of the Federal University of São Paulo, campus Baixada Santista, registered in Physical Education, Physiotherapy, Nutrition, Psychology, Social Work and Occupational Therapy programs. Results show that sensitive listening has affected students in a qualitative way in relation to subjectivity and future professional practice. There was appreciation of the provision of humanized care, breaking down prejudices and paradigms; creating therapeutic bonding; overcoming differences and understanding self from the life story of the other.
\end{abstract}

Keywords: Health education. Narration. Listening. Otherness. Humanization.

\footnotetext{
* Recorte da pesquisa de mestrado "A formação interprofissional em saúde e o processo de produção de narrativas: construindo caminhos de aprendizagem", que objetiva descrever e analisar o percurso feito pelos estudantes para produzir narrativas de histórias de vida com munícipes de regiões em vulnerabilidade social de Santos / Extracted from the Masters' degree research "Interprofessional education in health and the process of producing narratives: building learning pathways", that aimed to describe and analyze the trajectory of students while writing life-story narratives of citizens living in social vulnerability areas in Santos, SP, Brazil.

${ }^{1}$ Universidade Federal de São Paulo (UNIFESP), Santos, SP, Brasil. E-mail: <claudia_cmo@yahoo.com.br>.

${ }^{2}$ Universidade Portucalense Infante D. Hentique (UPT), Faculdade de Psicologia, Porto, Portugal.

${ }^{3}$ Universidade Federal de São Paulo (UNIFESP), Departamento de Gestão e Cuidado em Saúde, Santos, SP, Brasil.
} 


\section{Introdução}

A formação dos profissionais de saúde, centrada no modelo "tradicional ou bancário" (FREIRE, 2005), repercute hoje na despersonalização da relação de cuidar, ou seja, em um atendimento clínico focado na doença e nos aspectos biológicos do adoecimento, na tecnologia dura, na medicalização e na falta de exercício da capacidade de escuta do paciente. Nesse paradigma, há maior preocupação com a transmissão e reprodução de informações e com a fragmentação do conhecimento (FEUERWERKER, 2003; GOMES et al., 2010; GONZÁLEZ; ALMEIDA 2010; LOPES et al., 2007).

Embora a necessidade de mudanças no processo de formação seja muito discutida e tenha despertado para a criação de diversos programas de incentivo e tentativas de mudanças (CARVALHO; CECCIM, 2006; CECCIM; FEUERWERKER, 2004), como é o caso da aprovação das Diretrizes Curriculares Nacionais (DCN) dos cursos de graduação em saúde, entre 2001 e 2004, existe ainda uma grande dissonância entre o perfil de profissionais formados pelas instituições de ensino e aquele esperado para atuação no Sistema Único de Saúde (SUS), que é o principal empregador nessa área, de acordo com Almeida-Filho (2011).

As DCN traçam o perfil de um formando egresso/profissional com formação generalista, humanista, crítica e reflexiva. Na medida em que rompem com a "noção de currículo mínimo para a organização dos cursos de graduação" (CARVALHO; CECCIM, 2006, p. 16), as Diretrizes privilegiam não só as dimensões tecnológicas e técnicas para a formação desses profissionais, mas também aspectos psicossociais de seres humanos historicamente situados. Assim, esses documentos contemplam, além dos conteúdos específicos e técnicos, aqueles provenientes das Ciências Sociais e Humanas para o desenvolvimento pleno desses profissionais.

Diante desse cenário, torna-se cada dia mais urgente a implementação de novas possibilidades de formação que articule o ensino com as necessidades de saúde da população; que busque por novos espaços de aprendizagem; que não esteja centrada somente na doença, nas teorias e em suas meras aplicações, na reprodução de informações, no saber médico e exclusivamente na prescrição de medicamentos (CARVALHO; CECCIM, 2006; KASTRUP, 2013).

Nesse contexto, o câmpus Baixada Santista (BS) da Universidade Federal de São Paulo (UNIFESP), por meio de um projeto político-pedagógico inovador (UNIFESP, 2006), tem buscado o desenvolvimento de metodologias ativas de ensino que orientem os estudantes, desde os anos iniciais da vida acadêmica, à autonomia, à possibilidade de articulação entre teoria e prática, ao "mergulho na experiência" (KASTRUP, 2013) e que possibilitem a aproximação entre ensino e serviços de saúde, ao contato com o "corpo vivo". Em relação a essa interação, Carvalho e Ceccim (2006, p. 23, grifo do autor) esclarecem que:

Em muitos cursos da área da saúde só vamos enfrentar o corpo vivo no final da graduação, por meio dos estágios supervisionados, internatos e treinamento clínico, por exemplo. Isso complica tudo porque o corpo vivo é a pessoa, que carrega uma história, dilemas, sofrimentos, alegrias, gostos, necessidades, compreensões e cultura. Tudo se complica para o usuário porque aquele conhecimento dos primeiros anos, que está desvinculado da dinâmica das relações, organiza o olhar do estudante que, quando vai assistir, inicia por uma imagem de desseç̧ão do corpo e não pela escuta ou contato com a alteridade. 
Entre essas metodologias está a produção de narrativas com alunos do segundo ano dos seis cursos existentes: Educação Física, Fisioterapia, Nutrição, Psicologia, Serviço Social e Terapia Ocupacional. Esta atividade tem sido desenvolvida no Eixo Trabalho em Saúde (TS), Módulo Prática Clínica Integrada: análise de demandas e necessidades em saúde, com o objetivo de possibilitar a identificação de demandas e necessidades de saúde de moradores de regiões de maior vulnerabilidade social, na cidade de Santos, SP. A maior parte dos encontros é domiciliar e, para as visitas, professores e serviços de saúde selecionam os casos que serão escutados por duplas interdisciplinares de estudantes. A escuta é feita sem o apoio de gravador, a partir da qual os estudantes construirão uma narrativa escrita em duplas. Ao final, é feita a leitura desse texto ao morador que, após aprovação, poderá dar consentimento para que o material seja anexado ao seu prontuário, no serviço de saúde onde é acompanhado.

Nessa atividade, os estudantes são inseridos no contexto de vida desses moradores e, por isso, encontram-se imersos em suas histórias e ecologias de vida, ou seja, eles também participam na (re)organização de acontecimentos, no momento da escuta e escrita das narrativas.

Trata-se, portanto, da tentativa de criar proposições que valorizem a aprendizagem pela experiência do estranhamento daquilo que é inusitado e sobre o qual não se tem controle; enfim, pela experiência das contradições oferecidas pela vida:

[...] a exposição às áreas de maior vulnerabilidade social, o exercício da prática interprofissional nos encontros com as pessoas e com os serviços fazem parte de um processo que valoriza a experiência desde o início da graduação como pressuposto fundamental para a aprendizagem de um agir profissional cuidador implicado com a produção da vida. (CAPOZZOLO et al., 2013, p. 127).

De acordo com Kastrup (2001), a exposição às novas experiências não encontra um espaço de reconhecimento, mas sim de estranhamento e tensão entre o saber e a experiência nova. Desta forma, as experiências podem ser construídas e (re)inventadas. Aprender, então, não é um ato de adaptação, apenas, a um meio ambiente dado ou a um meio ambiente físico absoluto, mas é um ato que compreende a criação do próprio mundo.

Ao produzirem as narrativas, os estudantes tornam-se sensíveis às palavras do outro, por meio da escuta sensível, e mais vulneráveis a elas, o que os faz experimentar certas metamorfoses em suas subjetividades.

A autonarrativa é um ato discursivo que implica a pessoa toda, produtora de sentido contextualizado. Com efeito, o sentido de uma palavra está determinado pelo seu contexto, havendo "tantas significações possíveis quanto contextos possíveis"; ela está sempre repleta de "um conteúdo ou de um sentido ideológico ou vivencial". Segundo ele, a substância da língua é constituída "pelo fenômeno social da interação verbal, realizada através da enunciação ou das enunciações." (BAKHTIN, 2009, p. 99, 109, 127, grifo do autor).

Estudos mostram como a coconstrução de narrativas biográficas, de teor psicossomático e psicossocial, coloca a vivência singular e o contexto único da experiência no centro do cuidar, contribuindo para o tratamento de pacientes, a partir da interpretação partilhada do processo subjetivo de adoecimento, de adaptação à enfermidade, de ressonância emocional e das múltiplas transformações trazidas pelo adoecimento não apenas para aqueles que o vivenciam, mas também para os que constituem as redes informais/afetivas de apoio da pessoa adoecida. Tais 
estudos têm revelado também que as narrativas colaboram para o desenvolvimento da empatia dos profissionais, da confiança do paciente, da compaixão pela dor e pelo sofrimento daquele que requer cuidado (GREENHALGH; HURWITZ, 1999).

De acordo com Hydén (1997, p. 49, tradução nossa), "Uma de nossas mais poderosas formas para expressar sofrimento e experiências ligadas a esse sofrimento é a narrativa. A narrativa dá voz à dor do paciente de uma forma que está fora do domínio da voz biomédica."

A pessoa que apresenta uma enfermidade mostra-se apta a fornecer informações sobre seu corpo, não só enquanto espaço sensorial proprioceptivo ou autoafetivo, mas também como processo socioemocional e como representação cognitiva e simbólica, envolvendo estratégias de relação com o sofrimento e a dor, as crenças sobre saúde e doença (vida e morte), a história da emergência e desenvolvimento da sintomatologia, a percepção das condições etiológicas e das intervenções médicas e a autoavaliação da eficácia terapêutica (CHARON, 2006; GREENHALGH; HURWITZ, 1999).

Dessa forma, aprender a estabelecer uma relação interlocutiva de escuta e coconstrução das narrativas de histórias de vida significa acessar conteúdos; compreender o(s) mundo(s) subjetivos(s) de quem requer cuidado e saber interpretá-lo(s). Ao passo que essa narrativa é construída conjuntamente, escutar significa também que o cuidador passa a ter um contato mais íntimo com seu(s) próprio(s) mundo(s). Quanto mais esse cuidador (re)conhece o outro, mais se (re)conhece e, portanto, poderá tornar-se cada vez mais apto a acessar aquele de quem cuida e desenvolver a competência narrativa, cognitiva e emocional, aliada a uma ética de aproximação empática do paciente enquanto "narrador ferido" (wounded storyteller) (ENGEL et al., 2008; FRANK, 2013).

Nesse sentido, o objetivo deste artigo consiste em compreender e analisar os efeitos da escuta na formação de profissionais da saúde, por meio da produção conjunta de narrativas.

\section{Método}

Este artigo origina-se da pesquisa "A formação interprofissional em saúde e o processo de produção de narrativas: construindo caminhos de aprendizagem” (OLIVEIRA, 2014), cuja natureza é qualitativa, exploratória e analítica. O projeto foi aprovado pelo Comitê de Ética em Pesquisa da Universidade Federal de São Paulo (UNIFESP), Resolução nº 466, de 12/12/2012, do Conselho Nacional de Saúde, em 5/04/2013, Parecer nº 238.348.

O objetivo geral do estudo foi descrever e analisar o percurso feito pelos estudantes do $2^{\circ}$ ano de graduação dos cursos de Educação Física, Fisioterapia, Nutrição, Psicologia, Serviço Social e Terapia Ocupacional da UNIFESP-BS, para produzir narrativas de histórias de vida, em duplas interprofissionais, com moradores em regiões de maior vulnerabilidade social da cidade de Santos/São Paulo.

Os dados foram obtidos utilizando-se dois instrumentos de coleta de dados: questionário de múltiplas escolhas, aplicado a 146 estudantes matriculados no módulo investigado e 18 entrevistas semiestruturadas. Essas entrevistas foram gravadas, transcritas e analisadas de acordo com a técnica de Análise de Conteúdo, modalidade Análise Temática (BARDIN, 2011).

O questionário foi aplicado objetivando a caracterização dos participantes como leitores e escritores, em função de seus hábitos de leitura e escrita. Optou-se por nove questões 
fechadas, com respostas de múltiplas escolhas, por oferecerem maior uniformidade às respostas e por serem mais facilmente processadas (GIL, 2011).

Para a coleta de maior número possível de informações sobre o processo de escrita das narrativas, as entrevistas foram realizadas ao longo de um semestre, sendo aplicadas em três etapas: a primeira, ao início do módulo, com o objetivo de coletar dados sobre o conhecimento prévio de narrativas em saúde e sobre as possíveis dificuldades encontradas pelos estudantes para a escrita desse gênero textual. A segunda, após a supervisão feita em sala de aula com os docentes, no sentido de coletar informações sobre o processo de escrita, facilidades e dificuldades encontradas na prática. A terceira, ao final da elaboração da narrativa, com o propósito de obter informações sobre a contribuição da produção das narrativas para a vida dos estudantes.

A escolha metodológica pela entrevista em etapas possibilitou desvelar o processo do trabalho de escrita conjunta, de forma ampliada e aprofundada.

Os principais sentidos identificados no material coletado nas entrevistas permitiram que a Análise Temática fosse realizada em torno de três grandes temas: (1) Dificuldades e facilidades no processo de produção de narrativas; (2) A produção de narrativas no contexto interprofissional; (3) Impactos da experiência de produção de narrativas para os estudantes.

Para atender ao objetivo deste artigo, foram utilizados os dados coletados na Categoria 3, considerando-se a importância da aprendizagem de escuta fortemente destacada pelos estudantes.

Por razões éticas, os participantes foram identificados por seus cursos: FIS (Fisioterapia), NUT (Nutrição), EF (Educação Física), SS (Serviço Social), TO (Terapia Ocupacional) e Psicologia (PSI).

\section{Resultados e discussões}

\section{Escuta: uma competência narrativa e ética}

As narrativas são acontecimentos ou performances comunicacionais que se formam e transformam no encontro dialógico onde a experiência se converte em linguagem e símbolo dramatizado. Participar nesse evento discursivo constitui uma experiência de aprendizagem e desenvolvimento. Ora, a escuta, processo nuclear do encontro dialógico, foi indicada pelos alunos entrevistados como uma das aprendizagens mais significativas, desenvolvidas durante o processo de produção de narrativas.

De fato, a atividade proposta pelo módulo tem como alicerce o desenvolvimento da habilidade de saber escutar com atenção, conforme enfatizaram os alunos de Educação Física e Nutrição, combinando a narrativa a dois elementos fulcrais, distintivos de cada voz narrativa, isto é, a contextualização e a personalização diferenciadoras da subjetividade e do posicionamento focal dos narradores:

[...] eu acho que é o principal objetivo da narrativa é você escutar e entender o contexto... porque pra mim o que ficou foi isso que a narrativa...ela serve pra você entender o contexto que a pessoa vive $[. .].[\mathrm{EF}]$. 
[...] ouvir mesmo as pessoas... porque eu não acho que isso não é só uma qualidade para o profissional... né? eu acho que pra gente mesmo... a gente tem que saber ouvir melhor... é: ... saber lidar com as diferenças também... né. [NUT].

A escuta atenta caracteriza-se como uma apreensão totalizadora, um escutar-sentir a alteridade significativa na sua configuração holística. Assim, ela apoia-se na ressonância empática, na epifania comunicativa da totalidade da pessoa e, portanto, na integração multissensorial de todos os sentidos, na atitude fenomenológica de suspensão do julgamento e da interpretação com categorias extrínsecas ou a priori, para permitir uma hermenêutica imanente ao processo comunicativo, capaz de captar a constituição espontânea de sentido (GIORGI, 2009; LANGDRIDGE, 2007).

No processo de coconstrução das narrativas, os graduandos revelaram sentir-se gratificados por realizarem os encontros, mesmo que não pudessem oferecer "nada além da escuta". Neste sentido, escutar atentamente significa uma completa disponibilidade para a fala do outro, para a singularidade única de seus gestos e diferenças, exigindo do escutador a mobilização de afetos e raciocínios narrativos (FREIRE, 1996).

A escuta acompanhada de "compreensão empática" (empathic understanding), forma e transforma a sensibilidade dos sujeitos em interlocução, pois essa compreensão empática, na formulação clássica de Rogers (1989, 2003), supõe a assunção do "quadro de referência interno" (internal frame of reference) do outro, a percepção do mundo e de si próprio, segundo a percepção do outro, e o afastamento de "todas as percepções [derivadas] de um quadro de referência externo" (external frame of reference) ao sujeito/narrador da experiência.

Sendo assim, a sensibilização, vivenciada durante a escuta e por meio dela, propicia uma sintonia e uma sincronia afetivas que sustentam e orientam a compreensão empática. Ora, a compreensão empática articula e unifica, numa totalidade semântica coerente, a performance comunicativa verbal, paraverbal e não verbal, implicando apresentação física, proxêmica, cinética ou movimento somático-espacial, postura corporal, gestos, mímica facial, contato visual, prosódia e silêncio (CARRIÓ; JANSON, 2004; KNAPP; HORGAN, 2014; POYATOS, 2002).

O aluno de Terapia Ocupacional relata ter aprendido muito com o trabalho de escuta, ao atentar-se ao não verbal:

[...] eu aprendi bastante... a questão da escuta sensivel realmente isso acaba ocorrendo porque ou você se sensibiliza com o que você tá ouvindo... ou você não consegue tradůż $r$... não consegue transcrever a história do narrador não tem como você ficar imparcial com o que a pessoa te fala...então en acredito que foi muito positivo no processo da narrativa... no meu desenvolvimento [...] eu acredito que agora eu tenho um olhar mais atento... conforme a pessoa fala... ela se expressa não só pelo verbal... né? o não verbal é muito importante e pelos gestos você acaba vendo o que a pessoa quer demonstrar, o que ela realmente querfalar... o que ela tá sentindo... q que ela quer expressar naquele momento... a escuta sensivel, eu nunca tinha parado realmente para ouvir alguém e me sensibilizar com aquilo... pelo menos posso até ter ouvido... mas eu nunca tinha reparado no efeito disso... no resultado [...] [TO]. 
Estar completamente acessível ao que o outro tem a dizer, na formação em saúde, significa compreender o ser humano em um contexto mais amplo; ou ainda, do ponto de vista da integralidade. Valorizar o contexto de vida dos moradores para a compreensão de suas necessidades de saúde exprime a relevância de que os futuros profissionais estejam atentos não só aos sinais da enfermidade, mas também às crenças e aos valores desses mesmos moradores; seus temores e, enfim, sua relação cognitiva e emocional com o mundo que os cerca.

Os estudantes de Serviço Social e Fisioterapia enfatizaram essa importância, para ultrapassar os limites da atenção em saúde que separa o corpo do paciente de suas questões subjetivas; impasse presente no modelo tradicional do ensino superior em saúde:

[...] suprime o julgamento que a gente pode ter diante de uma determinada situação... você aprende quando você... é... vê a situação a partir do contexto geral... histórico... socioeconômico e cultural e... que a pessoa tá inserida [...] acho que foi muito interessante nesse aspecto de escuta sensivel... de aproximar da situação como um todo... [SS].

[...] não cair nesse reducionismo da doença... né? de enxergar no indivíduo só a doença do indivíduo... analisar o conjunto de crenças... emoções...valores dele... respeitar isso também e... de certo modo... tem influência também das emoģões ali na doença [...]. o indivíduo... ele é a história dele... né? ele é aquilo que foi marcado nele pelo tempo... né? então é importante ver esse lado também. [PSI].

Outro efeito do processo de produção de narrativas sobre os estudantes, e que se relaciona à atitude fenomenológica e à atividade de uma escuta voltada aos cinco sentidos, diz respeito ao rompimento de preconceitos e paradigmas. Uma aluna de Psicologia depara-se com essa ruptura, ao observar que um paciente do Núcleo de Apoio Psicossocial de Santos (NAPS) está inserido em um contexto social, político, econômico, cultural e histórico, tanto quanto ela:

[...] poxa vida... eu tenho tanto preconceito... mas en que não sou a mocinha da bistória... né? Então... por exemplo... a questão do gravador... en tentei demovê-lo da ideia... falei que não era o propósito... expliquei pra ele tudo... e ele falou que fażia questão... que ele queria demais... que a gente não perdesse nada... e eu falei "e a gente nem veio preparado pra isso... eu não tenho como fazer"... e ele falou "como não tem como fažer? você não tem celular? hoje em dia... qualquer celular grava"... ai en fiquei MORRENDO de vergonha... sabe? eu falei "Deus... é verdade... ele tá nesse mundo como eu... ele sabe que as coisas existem"... né? então foi a primeira paulada foi assim... primeiro contato [...] [PSI].

De acordo com Grossman e Cardoso (2006, p. 11), "a virtude da abordagem narrativa é o fato de sua utilização forçar os profissionais da saúde a exporem suas concepções e preconceitos, confrontá-los e, em última instância, trazer lealdade para o diálogo com o outro".

Em outro momento, o aluno de Educação Física faz uma reflexão sobre os seus paradigmas acerca das condições de vida de quem vive nas palafitas e das relações que se estabelecem nesse espaço. Observa-se que o estudante faz uma análise sobre a relatividade de suas próprias concepções éticas entre o que pode ser considerado bom ou ruim, de acordo com a perspectiva 
adotada por cada um, mostrando que compreender alguém requer descentração de si próprio e mudança de ângulo interpretativo/experiencial:

[...] Conbecer o lugar pra onde a gente foi que foi pras palafitas... então da primeira vez. que a gente foi pra mim foi um choque muito grande de como uma pessoa mora nesse lugar...como ela... [...] Então... como construção pessoal minha... foi muito interessante... ter outra visão... de moradia das pessoas mesmo [...] foi uma coisa que marcou muito a gente... toda hora tava entrando gente na casa e saindo e a gente nem sabia quem era... todo mundo conhecia e gostava dela... isso me fez.pensar assim "nossa [frase exclamativa] a gente mora e a gente nem conhece o nosso vizinhbo"... sabe? Então... quão ruim a gente acha que aquele lugar é e na verdade não... pode ser muito melhor do que onde a gente mora... isso é uma visão que a gente tem $[. .].[\mathrm{EF}]$.

Nos diversos relatos dos estudantes, durante as entrevistas, ficou evidente que o exercício da escuta atenta despertou neles o reconhecimento da necessidade de afastar-se de qualquer julgamento, avaliação, aprovação, reprovação ou críticas.

De acordo com a descrição teórica postulada por Day e Jesus (2013), o processo de desenvolvimento que se manifesta nos estudantes consiste essencialmente no acréscimo de complexidade afetiva, cognitiva e moral através da integração desse relativismo ou perspectivismo ideológico e axiológico que se opõe e se internaliza na situação dialógica.

Observa-se, contudo, que em determinados depoimentos os alunos deixavam-se influenciar pela forma como a história de vida era narrada, criando-se uma barreira para a compreensão daquilo que lhes estava sendo contado. Um exemplo disso é o caso de uma aluna, relatado pelo seu colega de dupla, diante do "mistério" que um munícipe fazia de alguns momentos de sua história de vida, preferindo ocultá-la:

[...] ele era uma pessoa misteriosa em alguns pontos [...] foi uma grande dificuldade pra gente... principalmente pra minha dupla porque ela não entendia como ele podia estar disposto a contar a história dele e não querer contar algo... então isso foi sendo construído por [...] supervisão até ela conseguir entender o processo de que ele tem direitos e que ele pode guardar os segredos que ele achar melhor... então a dificuldade que a gente teve na escrita... foi isso no começo [...] e ela não conseguia desenvolver a escrita... pulando essa parte [...] [TO].

Os graduandos denotaram ainda maior compreensão da importância da escuta para a criação do vínculo terapêutico entre profissionais da saúde e pacientes. Os recortes de fala dos alunos de Fisioterapia e Educação Física mostram que a escuta pode ser o lugar onde se dá o conhecimento do singular e a eficácia curativa da confiança, enquanto aliança vital, cultivada entre profissional da saúde e o paciente:

[...] fisioterapenta tem que escutar o paciente... tem que saberpra depois aplicar o exercicio e não ir só pelos livros... [...] a pessoa precisa confiar em você... se a pessoa não confiar... acho que o tratamento não vai ser bom... não vai ser como a pessoa espera [...] [FIS]. 
[...] quando você começa a pensar na pessoa... né... pensar na história da pessoa... conversar... conhecer a pessoa... ela te devolve o um trabalho muito melhor... até um pouquinho mais facilitado... mas... em questão de... resultado fica assim muito mais... completo $[\ldots][\mathrm{EF}]$.

A atividade proposta pela TS permite entender que escutar implica a oferta de um cuidado mais humanizado, na medida em que essa atividade pode evocar a responsabilização pela vida do outro, a compaixão, a bondade, a empatia e o respeito por aquele(a) que demanda cuidado.

Ainda em relação ao vínculo estabelecido com os moradores, ao serem questionados sobre o término das atividades e o rompimento desse vínculo com as pessoas acompanhadas, após a devolutiva das narrativas, a maioria dos graduandos expressou quais foram as ressonâncias dessa fase. Tal situação também se apresenta como relevante na formação dos alunos, pois, na prática, eles aprendem que é tão importante formar um vínculo com o paciente, quanto saber trabalhar emocionalmente com seu rompimento, quando o contexto do tratamento assim exigir, por quaisquer motivos:

ah... foi um pouco... difícil assim... porque a gente criou um vínculo com as pessoas e tudo mais... mas foi gratificante porque ele gostou...ele se emocionou em algumas partes da narrativa e a gente viu que, assim, o objetivo de construir a narrativa foi alcançado... sabe (frase interrogativa) foi bem gratificante... apesar de não ter mais contato com ele e tudo mais [...] [NUT].

[...] en particularmente fiquei triste por ter acabado... assim... porque eu achei muito legal e eu percebi... assim, tanto eu como minha dupla... a gente percebeu que... foi muito legal não só pra gente como pra ele também... né? pro senhor que a gente entrevistou e tal... e ele... assim... deu pra perceber que ele se sentia muito bem com a gente lá [...] eu fiquei com vontade de poder continuar alguma outra coisa... sabe? mesmo que não fossem as visitas... algum outro trabalho envolvendo essas pessoas... acho que seria legal. [NUT].

Outros, porém, sentiram-se aliviados, ao finalizar os encontros e o vínculo, devido à forte carga emocional com a qual tiveram de lidar e que, de forma dolorosa, ensinaram sobre si mesmos, como neste caso do aluno de Psicologia:

[...] eu gostei que tivesse acabado... sabe? pra mim não era prazeroso tá lá... não era uma coisa que eu ia "oba que legal ... hoje narrativa [frase exclamativa]... era sempre pesada... a bistória muito pesada... um ambiente que eu não gosto... não era fácil estar lá e fazer isso... então en fiquei aliviada por ter acabado...en achei bom que acabou... né? e assim... trago essas lições todas que eu vou carregar pra sempre... que foram MUITO importantes... mas não é um processo que eu vou ter saudade... foi duro pra mim... até entender... assim... me ver de uma maneira tão diferente... tão ruim...né? me dar conta... assim... de coisas que eu pensava e que eu achava...que não são bonitas... né? [PSI]. 
Ao estabelecerem um vínculo com o(s) munícipe(s), os graduandos que ofertaram cuidado, por meio da escuta, também foram afetados por esse mesmo cuidado, na medida em que sofreram transformações em sua subjetividade. Ou seja, ao ajudar o outro a (re)inventar-se, os estudantes também aprenderam com esse outro acerca de si mesmo.

\section{Alteridade: o outro dentro-de-si ou o si-próprio como alteração}

A escrita das narrativas no módulo Prática Clínica Integrada: análise e demandas de necessidades em saúde não envolve somente seus pontos facilitadores e/ou dificultadores, como se pressupunha, antes de iniciar as entrevistas. Essa afirmação baseia-se no fato de que a escrita das narrativas é resultado de todo um processo de encontros permeados pelas subjetividades de todos os "outros" envolvidos nesse caminho (serviços de saúde, colega de dupla e colegas de sala, docentes e quaisquer outros envolvidos na atividade). Por ser um trabalho em equipe, existe toda uma expectativa em relação às práticas que serão produzidas no "trabalho vivo em ato" (MERHY, 2013) e nas interações com os outros.

O que se observou é que a interação é a mais forte característica da atividade proposta pelo módulo, na medida em que o cuidado oferecido se faz na troca que está constituída pela linguagem, pelo agenciamento das relações e pela escuta atenta.

De acordo com Ayres (2004, p. 24), "[...] a busca ativa de projetos de felicidade daquele de quem se cuida, traz para o espaço do encontro terapêutico, potencializando-o, um processo de (re)construção identitária que implica mutuamente profissionais e usuários”. De fato, quem acompanha a reinvenção da identidade narrativa do outro pela palavra ou pela observação contextual, por um escutar multissensorial, pode participar de uma transformação mútua, quando está aberto para essa experiência, conforme ilustrado nesta afirmação do aluno de Serviço Social:

\section{[...] eu me desenvolvi por enquanto... o eu como pessoa... é... se eu quiser colocar alguma coisa de mais á́... como estudante [...] eu tô desenvolvendo muito o pessoal... e que vai ser um determinante pra dizerer qual vai ser a minha atuação como profissional. [SS].}

Como assinala Bakhtin (2009, p. 154), a pessoa que apreende a enunciação é "um ser cheio de palavras interiores" e sua "atividade mental" ou "o 'fundo perceptivo' é mediatizado para ele pelo discurso interior, e é por aí que se opera a junção com o discurso apreendido do exterior".

Alguns alunos chegaram desconfiados à primeira entrevista; às vezes fechados para a experiência da "aprendizagem inventiva" (KASTRUP, 2013), pleno de incertezas. Ao final, eles tinham sido visivelmente tocados pelos encontros, transformados por uma prática que quase não se sabia como terminaria, ainda que muito se tivesse planejado até chegar ao trabalho de campo.

Um exemplo que ficou muito evidente foi o de um aluno de Educação Física que, na primeira entrevista, expressava-se com poucas palavras e não demonstrava interesse em contribuir com a pesquisa, fornecendo respostas muito curtas. Porém, no decorrer da atividade do módulo, ele revelou que a atividade o fez revisitar sua própria narrativa de história de vida, em um processo de autorreconhecimento e de autoquestionamento reflexivo: 
[...] é quando você faz a narrativa [...] você começa a pensar sobre você mesmo... o que seria a minha narrativa... né? o que... que eu pensei muito assim da narrativa seria... se autoconhecer... se reconhecer a si... na verdade... porque às vezes a gente passa... a gente vive... a gente faz o que a gente faz... mas não para pra pensar sobre o que a gente far.... né ? por que a gente far. $[\ldots][\mathrm{EF}]$.

ao declarar que:

Kastrup (2013, p. 152) ressalta a ideia da transformação de subjetividade dos estudantes [...] ao experimentar o contato direto com os pacientes, com a equipe e com os serviços de saúde, os estudantes experimentam, por meio de uma atenção a si, virtualidades em sua própria prática, bem como ressonâncias e reverberações de experiências, que os afetam e acionam transformações em cada subjetividade.

Os alunos que experimentaram as transformações de sua subjetividade, ao serem expostos à escuta da história de vida do(s) munícipe(s), a um território totalmente diferente daquele a que estavam habituados e às relações com colegas e serviços de saúde, passam a ser a representação de um "mesmo".

Retoma-se aqui um recorte da fala do aluno de Educação Física:

[...] é quando você faz a narrativa [...] você começa a pensar sobre você mesmo... o que seria a minha narrativa... né? O que ... que eu pensei muito assim da narrativa seria... se autoconhecer... se reconbecer a si... na verdade... porque às vezes gente passa... a gente vive... a gente faz o que a gente far... mas num/num para pra pensar sobre o que a gente fa... né? por que a gente faz [...] [EF].

Essa reflexão alinha-se ao que foi destacado por Gentil (2010, p. xiii), na introdução de Tempo e narrativa de Ricoeur: "as obras de linguagem, em particular as narrativas, revelam-se mediadoras entre um ponto de partida e um ponto de chegada, entre uma determinada configuração do mundo e outra".

Pode-se afirmar que até mesmo a participação na pesquisa também agiu como um espaço reflexivo-hermenêutico, de autoaplicação do processo dialógico e narrativo.

O depoimento do aluno de Terapia Ocupacional ilustra essa asserção:

[...] ah, en gostei muito, en agradeço por poder participar da pesquisa... me fez refletir mais... o fato de ter que vir aqui ... ter que falar... de estarparticipando... é acaba pedindo pra você que você reflita mais a respeito... não é aquela coisa... você fez automaticamente passou... encerrou e acabou... então acho que veio me acrescentar bastante... tanto o módulo quanto a pesquisa ... por eu acabar me fazendo olhar atentamente [...] [TO].

Em busca de uma "hermenêutica do si", Ricoeur (2012, p. 418) utiliza o termo identidade "no sentido de uma categoria da prática", isto é, como modalidade da ação que altera o ator. Para ele, responder à pergunta "Quem fez tal ação"? é "contar a história de uma vida". A 
história contada diz o "quem" da ação e, portanto, a identidade do "quem" não é mais que uma "identidade narrativa", uma competência e uma performance de autonarração.

O nome próprio pode fornecer uma noção ilusória de identidade permanente, de que o sujeito é sempre o mesmo, desde o nascimento até a sua morte (RICOEUR, 2012), porém quando se entende esse sujeito como alguém que está sempre se (re)construindo, como um resultado de um estar no mundo, essa noção pode ser descartada.

Para resolver a questão da permanência no tempo, Ricoeur (2012) propõe uma dialética que articula a noção de identidade-idem ou identidade/mesmidade (mêmeté) de tipo substancial (ao modo do caráter e das disposições persistentes) e a identidade-ipse ou ipseidade (a qualidade de sipróprio com conteúdos fluidos e instáveis) que remete para a "identidade narrativa": o atornarrador que atribui a si próprio a ação/narração e que, com audácia ou com ilusão, promete permanecer fiel ao seu eu e aos seus outros. Em uma análise da obra Si-mesmo como um outro, de Ricoeur, publicado em 1990, Silva (2008, p. 2) ressalta que:

As mudanças ameaçam; o tempo apaga, mas nenhum dos dois desfaz o ipse do sujeito. O que permanece são fragmentos de relações entre ocorrências a respeito de um mesmo sujeito. Não o sujeito. Tais fragmentos são o si, isto é, o ipse, como um outro; como uma representação. Entre o si e uma história de vida há uma desigualdade ao mesmo tempo que uma cumplicidade e uma implicabilidade, pois ambos pressupõem alteridade em um grau tão íntimo que uma passa na outra; uma não pode ser pensada sem a outra, tanto que o si pode ser considerado o mesmo sendo outro.

A falta de um "reconhecer-se", em muitos casos, pode ser a sensação de um esvaziamento de um "si-mesmo" que se pensava imutável e que, ao perceber seu deslocamento, desestrutura-se. Portanto, reinventar-se não é um processo confortável; é doloroso; causa estranhamento; leva a um autoquestionamento. O processo de transformação, relatado pelos estudantes durante a atividade proposta pelo Módulo da TS, ocorre por meio de uma aprendizagem que, em sua dinâmica inventiva, semiótica e estética, desestrutura e surpreende. A declaração do aluno de Psicologia ilustra bem o processo de reflexão sobre si:

[...] eu não esperava ter [...] tantas coisas que surtissem efeito em mim... né? quando você falar de fazer a narrativa de alguém... parece que você fica mais como ouvinte e depois vai transcrever isso sem se envolver... mas... assim... eu... pessoalmente... acho que tive um crescimento muito grande... e de uma maneira bem dolorosa... né? porque eu nunca quis e continuo não querendo trabalhar no NAPS... apesar de fazer psicologia... en nunca quis saúde mental... e aí eu percebi que eu tinha uma visão estereotipada do doente mental [...] e aí isso me dá a medida do quanto eu sou arrogante... o quanto eu me acho melhor... e não é bom você se deparar com isso, né? [...] [PSI].

Outro recorte de fala que merece ser destacado é o do aluno de Serviço Social que ao mesmo tempo em que demonstra satisfação, ao perceber suas próprias transformações, reconhece que essa nova configuração de si acabou provocando o afastamento daqueles que não conseguiam mais identificar-se com suas novas concepções: 
[...] eu sempre falava que eu conhecia a pobreza e eu conbeci miséria... isso... me modificon muito... só que aí você também muda a sua forma de pensar [...] foi melhor pro men crescimento como ser bumano, também tá sendo difícil porque as pessoas se afastam da gente [...] não tinha NOÇ̃̃O das dificuldades que a pessoa atravessa... então como en tive oportunidade diferente... você acaba julgando que todo mundo também tem [...] eu gostei desse meu crescimento... en gosto da pessoa que eu sou hoje em dia... mas en fico triste de ter perdido tantos amigos. [SS].

O aluno do Curso de Psicologia se reconhece "outro", em "um crescimento muito grande", ao constatar que "realidades diferentes" existem e que o preconceito não será a saída para aprender a trabalhar com essas realidades:

[...] você perceber que tinha tanto preconceito... que você era tão ignorante acerca do assunto... e refletir sobre isso e tentar ter uma visão diferenciada... e transpor isso pra outros lugares... porque por mais que eu não queira trabalhar com saúde mental... vou ser um profissional de saúde e eu vou lidar com realidades diferentes da minha... e a minha não é o melhor padrão... então... de repente... né? [...] Foi um crescimento muito grande... en achei uma experiência muito rica [...] [PSI].

Encerrando as discussões propostas, fica aqui uma belíssima reflexão do educador brasileiro Paulo Freire, em seu livro Pedagogia da autonomia, segundo a qual o conhecimento de si mesmo passa antes pela superação de diferenças:

[...] é na minha disponibilidade permanente à vida a que me entrego de corpo inteiro, pensar crítico, emoção, curiosidade, desejo, que vou aprendendo a ser eu mesmo em minha relação com o contrário de mim. E quanto mais me dou à experiência de lidar sem medo, sem preconceito, com as diferenças, tanto melhor me conheço e construo meu perfil. (FREIRE, 1996, p. 134).

A atividade de escrita de narrativas, desenvolvida no Eixo TS, deixa muitas lições sobre uma aprendizagem permeada pelo agenciamento entre serviço de saúde; docentes; alunos; e moradores. Trata-se de uma atividade hermenêutica, na medida em que permite aos estudantes a compreensão empática do(s) outro(s) e consequente aprendizagem acerca dele(s); de suas necessidades de saúde, para o oferecimento de cuidado integral; maior compreensão de si mesmo e dos aspectos que envolvem sua atuação como futuro profissional da saúde.

\section{Considerações Finais}

Este artigo buscou compreender e analisar os efeitos da escuta, na formação de educadores físicos, fisioterapeutas, nutricionistas, psicólogos, terapeutas ocupacionais e assistentes sociais, por meio da estimulação da competência narrativa, cognitiva e emocional nos estudantes.

O estudo traz um relevante contributo para a formação em saúde, na medida em que apresenta uma experiência nova com estudantes de saúde, já na fase inicial da vida acadêmica, 
na qual eles são colocados em contato com a alteridade, em cenários de aprendizagem reais, por meio da articulação entre serviço de saúde e instituição formadora.

A experiência mostra também que a coconstrução de narrativas de histórias de vida pode apresentar-se como uma ferramenta metodológica eficaz para a formação, na medida em que desperta o estudante para a importância de se desenvolver a escuta atenta, como elemento fundamental do encontro dialógico entre futuros profissionais e usuários dos serviços de saúde.

De acordo com os resultados, a escuta sensível, apoiada na compreensão empática e na integração de todos os sentidos, pode (trans)formar a sensibilidade dos sujeitos envolvidos na interlocução, a partir de uma nova percepção de si e do outro.

Quanto mais (re)conhece o outro, mais o futuro profissional passa a (re)conhecer-se em suas próprias fragilidades, com isso, ele torna-se mais apto à superação de preconceitos, de paradigmas e das diferenças, além de estar mais bem preparado para a interpretação dos sinais da enfermidade.

Os estudantes demonstraram maior preocupação na oferta de cuidado humanizado, pois a coconstrução das narrativas evocou neles a responsabilização, a compaixão e a empatia pelos moradores.

A atividade de escuta ativa na graduação em saúde revela, enfim, que os estudantes podem estar mais aptos ao desenvolvimento e fortalecimento de vínculo terapêutico com seus pacientes, na medida em que se mostram mais abertos e receptivos para a oferta do cuidado integral, a partir da compreensão de fatores que extrapolam aspectos do adoecimento meramente biológico.

\section{Referências}

ALMEIDA-FILHO, N. Ensino superior e os serviços de saúde no Brasil. The Lancet, London, p. 6-7, série saúde no Brasil, 2011. Disponível em: <http://www.abc.org.br/IMG/ pdf/doc-574.pdf>. Acesso em: 26 fev. 2016.

AYRES, J. R. C. M. O cuidado, os modos de ser (do) humano e as práticas de saúde. Saúde e Sociedade, São Paulo, v. 13, n. 3, p. 16-28, 2004. Disponível em: <http://dx.doi. org/10.1590/S0104-12902004000300003>. Acesso em: 18 out. 2016.

BARDIN, L. Análise de conteúdo. Lisboa: Edições 70, 2011.

BAKHTIN, M. Marxismo e filosofia da linguagem. São Paulo: Hucitec, 2009.

CAPOZZOLO, A. A. et al. Formação descentrada na experiência. In: CAPOZOLLO, A.; CASETTO, S. J.; HENZ, A. (Org.). Clínica comum: itinerários de uma formação em saúde. São Paulo: Hucitec, 2013. p. 124-150.

CARRIÓ, S.; JANSON, J. Habilidades narrativas en la formación de profesionales de la salud: el entrenamiento de la escucha. Revista del Hospital Italiano de Buenos Aires, Buenos Aires, v. 30, n. 2, p. 76-77, 2004. Disponível em: <http://www.hospitalitaliano.org. ar/archivos/noticias_attachs/47/documentos/8758_76-77-educacion-30-2-2010.pdf $>$. Acesso em: 25 fev. 2016. 
Histórias de vida e compreensão empática: ...

CARVALHO, Y. M.; CECCIM, R. B. Formação e educação em saúde: aprendizados com a saúde coletiva. In: CAMPOS, G. W. S. et al. (Org.). Tratado de saúde coletiva. São Paulo: Hucitec, 2006. p. 149-182.

CECCIM, R. B.; FEUERWERKER, L. C. M. Mudança na graduação das profissões de saúde sob o eixo da integralidade. Cadernos de Saúde Pública, Rio de Janeiro, v. 20, n. 5, set-out, p. 1400-1410, 2004. Disponível em: <http://dx.doi.org/10.1590/S0102311X2004000500036>. Acesso em: 18 out. 2016.

CHARON, R. Narrative medicine: honoring the stories of illness. Oxford: Oxford University Press, 2006.

DAY, J.; JESUS, P. Epistemic subjects, discursive selves, and dialogical self theory in the psychology of moral and religious development. Journal of Constructivist Psychology, New York, v. 26, n. 2, p. 137-148, 2013.

ENGEL, J. et al. Narrative in health care. Abingdon: Radcliffe, 2008.

FEUERWERKER, L. Educação dos profissionais em saúde hoje: problemas, desafios, perspectivas e as propostas do Ministério da Saúde. Revista da ABENO, Brasília, v. 3, n. 1, p. 24-27, 2003.

FRANK, A. The wounded storyteller: body, illness, and ethics. 2nd. ed. Chicago: Chicago University Press, 2013.

FREIRE, P. Pedagogia da autonomia: saberes necessários à prática educativa. São Paulo: Paz e Terra, 1996.

Pedagogia do oprimido. Rio de Janeiro: Paz e Terra, 2005.

GENTIL, H. S. Introdução. In: RICOEUR, P. Tempo e narrativa. São Paulo: WMF Martins Fontes, 2010. v. 1, p. xi-xxii.

GIL, A. C. Métodos e técnicas de pesquisa social. São Paulo: Atlas, 2011.

GIORGI, A. The descriptive phenomenological method in psychology: a modified husserlian approach. Pittsburgh: Duquesne University Press, 2009.

GOMES, M. P. C. et al. O uso de metodologias ativas no ensino de graduação nas ciências sociais e da saúde - avaliação dos estudantes. Ciência \& Educação, Bauru, v. 16, n. 1, p. 181-198, 2010. Disponível em: <http://dx.doi.org/10.1590/S1516-73132010000100011>. Acesso em: 18 out. 2016.

GONZÁLEZ, A. D.; ALMEIDA, M. J. Movimentos de mudança na formação em saúde: da medicina comunitária às diretrizes curriculares. Physis Revista de Saúde coletiva, Rio de Janeiro, v. 20, n. 2, p. 551-570, 2010.

GREENHALGH, T.; HURWITZ, B. Narrative based medicine: why study narrative? British Medical Journal, London, v. 318, n. 7175, p. 48-50, 1999. Disponível em: <http:/ /www. ncbi.nlm.nih.gov/pmc/articles/PMC1114541/>. Acesso em: 25 fev. 2016. 
Oliveira, C.; Jesus, P.; Junqueira, V.; Uchôa-Figueiredo, L. R.

GROSSMAN, E.; CARDOSO, M. H. C. A. As narrativas em medicina: contribuições à prática clínica e ao ensino médico. Revista Brasileira de Educação Médica, Rio de Janeiro, v. 30, n. 1, p. 6-14, 2006. Disponível em: <http://dx.doi.org/10.1590/S0100$55022006000100002>$. Acesso em: 18 out. 2016.

HYDÉN, L. C. Illness and narrative. Sociology of Health \& Illness, Chichester, v. 19, n. 1, p. 48-69, 1997.

KASTRUP, V. Aprendizagem, arte e invenção. Psicologia em Estudo, Maringá, v. 6, n. 1, p. 17-27, 2001. Disponível em: <http://dx.doi.org/10.1590/S1413-73722001000100003>. Acesso em: 18 out. 2016.

- Um mergulho na experiência: uma política para a formação dos profissionais em saúde. In: CAPOZOLLO, A.; CASETTO, S. J.; HENZ, A. (Org.). Clínica comum: itinerários de uma formação em saúde. São Paulo: Hucitec, 2013. p. 151-162.

KNAPP, M.; HORGAN, T. Nonverbal communication in human(m) interaction. 8th. ed. Boston: Wadsworth, 2014.

LANGDRIDGE, D. Phenomenological psychology: theory, research and method. New York: Pearson Prentice Hall, 2007.

LOPES, S. R. S. et al. Potencialidades da educação permanente para a transformação das práticas de saúde. Comunicação em Ciências da Saúde, Brasília, v. 18, n. 2, p. 147-155, 2007. Disponível em: <http://www.dominioprovisorio.net.br/pesquisa/ revista/2007Vol18_2art06potencialidades.pdf>. Acesso em: 25 fev. 2016.

MERHY, E. E. Vivenciar um campo de formação de profissionais de saúde: dobrando em mim o fazer da UNIFESP-Baixada Santista. In: CAPOZOLLO, A.; CASETTTO, S. J.; HENZ, A. (Org.). Clínica comum: itinerários de uma formação em saúde. São Paulo: Hucitec, 2013. p. 19-34.

OLIVEIRA, C. M. A formação interprofissional em saúde e o processo de produção de narrativas: construindo caminhos de aprendizagem. 2014. 164 f. Dissertação (Mestrado em Ensino em Ciências da Saúde) - Universidade Federal de São Paulo, Santos, 2014.

POYATOS, F. Nonverbal communication across disciplines. Amsterdam: John Benjamins, 2002. (v. 2: Paralanguage, kinesics, silence, personal and environmental interaction).

RICOEUR, P. Tempo e narrativa. São Paulo: WMF Martins Fontes, 2012. 3 v.

ROGERS, C. Client-centered therapy: its current practice, implications and therapy. London: Constable, 2003.

Mifflin, 1989.

On becoming a person: a therapist's view of psychotherapy. Boston: Houghton 
SILVA, D. S. [Resenha]. RICOEUR, Paul. O si-mesmo como um outro. Trad. Luci Moreira Cesar. Campinas: Papirus, 1991. Letras de Hoje, Porto Alegre, v. 43, n. 4, p. 103-108, 2008. Disponível em: < http://revistaseletronicas.pucrs.br/ojs/index.php/fale/article/ view/5636/4110>. Acesso em: 18 out. 2016.

UNIFESP. Instituto de Saúde e Sociedade. A educação interprofissional na formação em saúde: a competência para o trabalho em equipe e para a integralidade no cuidado. In:

Projeto político pedagógico. Santos, 2006. Disponível em: <http://www.unifesp. $\mathrm{br} /$ campus/san7/todas-noticias/415-projeto-politico-pedagogico-do-campus-baixadasantista-e-citado-no-relatorio-final-da-global-ipe>. Acesso em: 25 de fev. 2016. 